\title{
Pharmacodynamics and Medicinal Chemistry of an External Chinese Herbal Formula for Mammary Precancerous Lesions
}

\author{
Ruixue Chen, ${ }^{1}$ Guijuan Zhang, ${ }^{2}$ Yi Ma, ${ }^{3}$ Fengjie Bie, ${ }^{1}$ Hongxia Fan, ${ }^{1,4}$ and Min $\mathrm{Ma}^{1}$ \\ ${ }^{1}$ School of Chinese Medicine, Jinan University, Guangzhou, Guangdong 510632, China \\ ${ }^{2}$ The First Affiliated Hospital of Jinan University, Guangzhou, Guangdong 510630, China \\ ${ }^{3}$ Institute of Biomedicine, Department of Cellular Biology, Guangdong Province Key Lab of Bioengineering Medicine, Jinan University, \\ Guangzhou, Guangdong 510632, China \\ ${ }^{4}$ College of Pharmacy, Jinan University, Guangzhou, Guangdong 510632, China
}

Correspondence should be addressed to Min Ma; tmamin@jnu.edu.cn

Received 24 March 2017; Accepted 24 May 2017; Published 24 July 2017

Academic Editor: Ken Yasukawa

Copyright (C) 2017 Ruixue Chen et al. This is an open access article distributed under the Creative Commons Attribution License, which permits unrestricted use, distribution, and reproduction in any medium, provided the original work is properly cited.

Ruyan Neixiao Cream (RYNXC) is a traditional Chinese herbal formula for treating mammary precancerous disease. This study was carried out to investigate in vivo anticancer effect of RYNXC and multiple constituents. 32 virginal Sprague-Dawley rats were randomly divided into blank control group (BC), mammary precancer models group (MODEL), tamoxifen group (TAM), and Ruyan Neixiao Cream group (RYNXC). TAM was intervened by tamoxifen; RYNXC was intervened by Ruyan Neixiao Cream. The chromatographic separation was performed by high performance liquid chromatography (HPLC) coupled with mass spectrometry (MS). RYNXC showed significant improvement in erythrocyte aggregation index (EAI), hematocrit (HCT), fibrinogen (FIB), spleen coefficient, and uterus coefficient compared with MODEL. In RYNXC and TAM groups, atypical hyperplasia was observed in pathological mammary tissues; meanwhile in MODEL group, ductal carcinoma was observed in situ. Moreover, fifteen compounds were characterized according to HPLC-MS data, including organic acids, tannin, alkaloid, volatile oil, anthraquinones, and flavonoids. The study suggests that RYNXC was an effective Chinese herbal formula for mammary precancerous lesions and provides a scientific basis for the quality standard and the pharmacology of RYNXC. It will be beneficial to the future clinical application of RYNXC.

\section{Introduction}

Breast cancer has been ranked first in women's malignancy around the world, while the mortality and morbidity were increasing [1]. The American Society of Clinical Oncology (ASCO) recommended aromatase inhibitor (AI) for 5 years or AI for 2 to 3 years and changing into tamoxifen (TAM) for 5 years in all as initial choice to patients who were diagnosed with hormone-receptor-positive breast cancer. A clinical study from University of Oxford reported that, for T1N0 patients with low, middle, and high grade, the risks of distant recurrence in 5 14 years were 5\%, 8\%, and 10\%, and the local recurrence rates were $12 \%, 15 \%$, and $17 \%$; even with endocrine therapy for 5 years, the recurrence risks remained [2]. World Health Organization (WHO) reported that precancerous lesions were diseases in which the risks developing into cancer were more than $20 \%$. It is known that the development of breast cancer is of multiple stages: benign hyperplasia, atypical hyperplasia, followed by carcinoma in situ, and finally invasive carcinoma [3,4]. That is to say, diseases may develop into cancer at the stages of atypical hyperplasia and carcinoma in situ [5].

In this study, rats' model of mammary precancerous lesions was established by DMBA plus estrogen and progesterone. DMBA is a commonly used chemical carcinogen for chemical induction of mammary cancer model [6]. Breast is a target organ of hormone; the incidence of breast cancer may be increasing with the increasing levels of estrogen and progesterone; therefore, rats' model of mammary precancerous lesions was established by regulating intervention time and dosage of estrogen and progesterone [7]. 
Studies showed that therapies could effectively reduce the incidence of malignant tumor, for example, traditional Chinese medicine (TCM) $[8,9]$. In TCM, breast precancerous lesion is considered equivalent to the term " $\mathrm{Ru} \mathrm{Pi}$," which was described in the "General Treatise on the Cause and Symptoms of Diseases" (Chinese name in pinyin is "Zhu Bing Yuan Hou Lun") in the Sui Dynasty. TCM is characterized by syndrome differentiation. In this regard, "depression of liver and deficiency of spleen, stasis of blood, and thoroughfarecontrolling disharmony" are considered to be the basic pathogenic factors of mammary precancerous lesions. Therefore, relieving the suppressed liver and replenishing the spleen energy, activating blood circulation, and regulating the thoroughfare for anticancer treatment are the most important therapies in the treatment of mammary precancerous lesions.

Ruyan Neixiao Cream (RYNXC) was invented by School of Chinese Medicine (patent applied number: 201110029344.1), Jinan University (Guangzhou, China). The herbs in RYNXC were modified from the well-known traditional Chinese prescription "Yindu Neixiao Pulvis" which originated from the "Yao Lian Qi Mi" in 1920-1940 and is a Chinese herbal formula that has been used for a long time in the external treatment of surgical diseases, including breast cancer. RYNXC consists of multiple traditional Chinese herbs that have been widely used in oral decoction in clinic. However, the external preparation of RYNXC has not been applied. Therefore, pharmacological effect and chemical constituents of RYNXC are required so as to popularize its clinical application.

\section{Materials and Methods}

2.1. Reagents and Preparation. 7,12-Dimethylbenz[a]anthracene (DMBA, Tokyo Chemical Industry Co., Ltd., Japan) was dissolved in sesame oil by $7 \mathrm{mg} / \mathrm{ml}$ ratio, followed by Estradiol Benzoate injection, $1 \mathrm{ml} / 2 \mathrm{mg}$ (Shanghai GM Pharmaceutical Co., Ltd., China), and progesterone injection, $1 \mathrm{ml} / 10 \mathrm{mg}$ (Zhejiang Xianju Pharmaceutical Co., Ltd., China). Tamoxifen was purchased from Chi-Fei Chemical Co., Ltd. (Wuhan, China). Ointment was prepared by PEP4000, PEP400, and propylene glycol. Methanol was of analytical reagent grade (Sigma-Aldrich, St. Louis., MO, USA). Formic acid was of HPLC grade (Dikma Technologies, USA). HPLC-grade water was prepared using a Milli-Q water purification system (Millipore, USA).

The herb extractum of RYNXC was prepared in School of Chinese Medicine, Jinan University (Guangzhou, China). Fifteen standards were used as reference substances (RS): gallic acid (RS1), cianidanol (RS2), chlorogenic acid (RS3), tetrahydropalmatine (RS4), rosmarinic acid (RS5), quercetin (RS6), luteolin (RS7), eugenol (RS8), kaempferol (RS9), apigenin (RS10), aloe-emodin (RS11), rhein (RS12), emodin (RS13) (Chengdu Pufei De Biotech Co., Ltd., China), 11-keto$\beta$-boswellic acid (RS14) (Beijing Zhongke Yiyou Institute of Chemical Technology, China), and 3-acetyl-11-keto- $\beta$ boswellic acid (RS15) (Shanghai Yuanye Biotechnology Co., Ltd., China). The purity of all the reference substances is $\geq 98 \%$ and the chemical structures are shown (Figure 1). Stock solutions $(200 \mu \mathrm{g} / \mathrm{ml})$ of the RS were prepared by dissolving in methanol and storing at $4^{\circ} \mathrm{C}$ until use.

Powdered samples of all herbs were prepared. Firstly, all the herbs' powders were mixed and heated for reflux extraction by $60 \%$ ethanol water with the ratio of $1: 10(\mathrm{w}: \mathrm{v})$ for 90 minutes; then the residue was filtered and decocted with $60 \%$ ethanol water twice as the first time. The filtrate was removed by a rotary evaporation apparatus and then dried in a vacuum oven to form the dry extractum. The dried extractum was extracted with ether with the ratio of $1: 30$ $(\mathrm{w}: \mathrm{v})$ in an ultrasonic water bath for $10 \mathrm{~min}$ at $37^{\circ} \mathrm{C}$ with 1 hour of standing twice. The ether extracts were combined and evaporated until dryness. Then the residue was dissolved in $\mathrm{MeOH}$ with the ratio of $1: 10(\mathrm{w}: \mathrm{v})$. At last, the solution was centrifuged at $12000 \mathrm{r} / \mathrm{min}$ for 5 minutes and filtered through a Strata ${ }^{\mathrm{TM}}$ C18-E solid-phase extraction (SPE) column $(55 \mu \mathrm{m}$, 70 A, Phenomenex, USA) before injection into the HPLC system.

2.2. Instrumentation. Instrumentation included biological microscope (Leica DM6000B, Germany), slicing machine (Leica AS-325, Germany), slide drier (Leica 202-2, Germany), centrifugal machine (Sigma 2-16P, Beijing, China), Milli-Q Academic System (Millipore, USA), Dionex UltiMate 3000 Rapid Separation LC system (Dionex, USA), Thermo Scientific Dionex UltiMate 3000 Rapid Separation Diode Array Detector, an evaporative light scattering detector (Alltech, USA), and AmaZon SL electrospray ionization ion trap mass spectrometer (Bruker Daltonics, GER).

2.3. Animals. 32 SPF level 8-week-old virginal SpragueDawley rats (weight: 200-250 g) were purchased from Experimental Animal Center, Guangzhou University of Traditional Chinese Medicine (approval number SCXK (Yue) 20132234). All the animals were maintained in an environmentally controlled clean air room with 12-hour light and 12-hour dark cycle, with temperature of $20 \sim 25^{\circ} \mathrm{C}$ and relative humidity of $60-90 \%$. The rats were fed whole value grain feedstuff and were given access to tap water ad libitum. Treatment began one week after arrival. The animal experiments were conducted in accordance with the Guide for the Care and Use of Laboratory Animals (2008, Washington, DC). The protocols for the animal studies were also reviewed and approved by the Experimental Animal Ethics Committee of Jinan University.

The rats were randomly divided into blank control group (BC, $n=8$ ), mammary precancer models group (MODEL, $n=8$ ), tamoxifen group (TAM, $n=8$ ), and Ruyan Neixiao Cream group (RYNXC, $n=8$ ). Before cyclic drugs, BC group was given a single gavage of sesame oil $(1 \mathrm{mg} / 100 \mathrm{~g})$; MODEL, TAM, and RYNXC groups were given the same dosage of sesame oil with DMBA $7 \mathrm{mg}$. Then, for 5 days per cycle, BC and MODEL groups were smeared ointment $(0.2 \mathrm{~g})$ with nothing around the breasts, TAM group was smeared ointment with tamoxifen $(0.2 \mathrm{~g})$, and RYNXC group was smeared ointment with Ruyan Neixiao Cream (0.2 g) each day. Meanwhile, at first 3 days, BC group was injected with oil $(0.25 \mathrm{ml} / \mathrm{kg})$ and MODEL, TAM, and RYNXC groups were injected with Estradiol Benzoate $(0.5 \mathrm{mg} / \mathrm{kg})$. On the 4 th 
<smiles>O=C(O)c1cc(O)c(O)c(O)c1</smiles>

RS1<smiles>Oc1cc(O)c2c(c1)O[C@H](c1ccc(O)c(O)c1)[C@H](O)C2</smiles>

RS2<smiles>O=C(/C=C/c1ccc(O)c(O)c1)O[C@H]1C[C@H](C(=O)O)C[C@H](O)[C@H]1O</smiles>

RS3<smiles>O=c1cc(-c2ccc(O)c(O)c2)oc2cc(O)cc(O)c12</smiles>

RS7<smiles>O=C1c2cccc(O)c2C(=O)c2c(O)cc(CO)cc21</smiles>

RS11

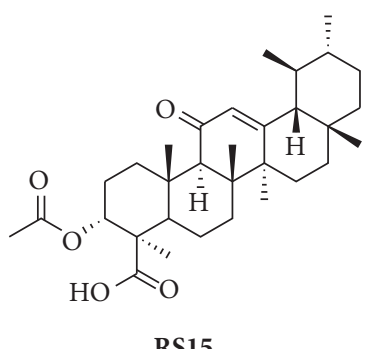

RS15<smiles>COc1cc2c(cc1OC)[C@@H]1Cc3ccc(OC)c(OC)c3CN1CC2</smiles>

RS4<smiles>O=C(/C=C/c1ccc(O)c(O)c1)O[C@H](Cc1ccc(O)c(O)c1)C(=O)O</smiles>

RS5<smiles>O=c1c(O)c(-c2ccc(O)cc2)oc2cc(O)cc(O)c12</smiles>

RS9<smiles>Cc1cc(O)c2c(c1)C(=O)c1cc(O)cc(O)c1C2=O</smiles>

RS13<smiles>O=c1cc(-c2ccc(O)cc2)oc2cc(O)cc(O)c12</smiles>

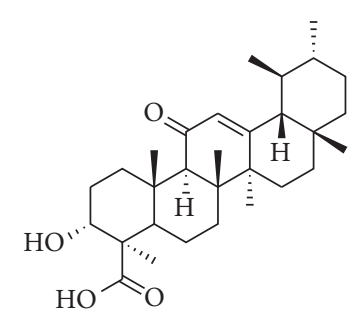

RS14<smiles>C=CCc1ccc(O)c(OC)c1</smiles><smiles>O=C(O)c1cc(O)c2c(c1)C(=O)c1cccc(O)c1C2=O</smiles>

RS12

FIGURE 1: Chemical structures of the reference substances (RS).

day, BC group was injected with oil $(0.4 \mathrm{ml} / \mathrm{kg})$ and MODEL, TAM, and RYNXC groups were injected with progesterone $(4 \mathrm{mg} / \mathrm{kg})$. On the 5 th day, there was only observation.

2.4. Detection of Indexes. All rats' physiological conditions, symptoms, and signs of drug toxicity were daily observed, including appetite, hair, weight, and nipple color and shape. After 60 days' intervention, the microcirculation perfusion of rats' breast tissues was observed. Blood was obtained from the abdominal aorta for the observation of hemorheology. The spleen tissues, liver tissues, and uterus tissues were rapidly removed and washed with saline at $4^{\circ} \mathrm{C}$. Breast tissues were dissected and fixed for 24 hours in 10\% neutral buffered formalin and then stained with hematoxylin-eosin (H\&E) staining and classified according to criteria of references. The remaining tissues were stored at $-80^{\circ} \mathrm{C}$ for later use.

HPLC was performed on a COSMOSIL 5C18-MS-II reverse-phase column $(4.6 \mathrm{~mm} \times 250 \mathrm{~mm}, 5 \mu \mathrm{m}$, Nacalai, Japan). The mobile phase consisted of $0.1 \%(\mathrm{v} / \mathrm{v})$ formic acid in water (A) and methanol (B). A gradient programme was used as follows: $0-46 \mathrm{~min}, 35-53 \% \mathrm{~B}$; $46-56 \mathrm{~min}, 53 \%-68 \%$ B; $56-71 \mathrm{~min}, 68-80 \% \mathrm{~B}$; 71-81 min, $80-90 \%$ B; $81-91 \mathrm{~min}$, 90-100\% B; and 91-111 min, 100\% B. A 15-minute postrun equilibration back to the initial mobile phase composition was included after each analysis. All mass spectra were acquired in the positive and negative ion modes. The capillary was at $4500 \mathrm{~V}$, the end plate offset was $500 \mathrm{~V}$, the nebulizer was $15.0 \mathrm{psi}$, dry gas was provided at $8.0 \mathrm{~L} / \mathrm{min}$, the dry gas temperature was $200^{\circ} \mathrm{C}$, and the scan range was $50-2200 \mathrm{~m} / z$.

2.5. Statistical Analysis. All data were analyzed by SPSS 17.0 and Microsoft Excel 2007. Experimental data were analyzed by One-Way ANOVA Test and the experimental data were expressed as mean and standard deviation $(\bar{X} \pm \mathrm{SD})$. Homogeneity of variances was conducted by two-tailed test. If the variances were homogeneous $(P>0.1)$, Newman-Keuls test was used to calculate the experimental data. If the variances were not homogeneous $(P<0.1)$, Tamhane's T2 test was used to calculate the experimental data. $P$ value $<0.05$ was considered statistically significant. 
TABLE 1: Results of microcirculation perfusion $(n=16, \bar{X} \pm \mathrm{SD})$.

\begin{tabular}{lc}
\hline Group & Microcirculation perfusion \\
\hline BC & $163.94 \pm 44.57$ \\
MODEL & $121.22 \pm 28.01^{\triangle}$ \\
TAM & $128.48 \pm 50.04^{\triangle}$ \\
RYNXC & $131.2 \pm 26.64^{\triangle}$
\end{tabular}

${ }^{\triangle} P<0.05$ versus $B C$.

TABLE 2: Results of hemorheology in rats $(n=8, \bar{X} \pm$ SD).

\begin{tabular}{|c|c|c|c|}
\hline Group & HCT & FIB & EAI \\
\hline $\mathrm{BC}$ & $0.3 \pm 0.02$ & $2.03 \pm 0.09$ & $2.36 \pm 0.11$ \\
\hline MODEL & $0.46 \pm 0.02^{\triangle}$ & $2.88 \pm 0.21^{\triangle}$ & $2.51 \pm 0.03^{\triangle}$ \\
\hline TAM & $0.40 \pm 0.02^{\triangle \boldsymbol{\Lambda}}$ & $2.21 \pm 0.17^{\triangle \boldsymbol{\Lambda}}$ & $2.42 \pm 0.05^{\boldsymbol{\Lambda}}$ \\
\hline RYNXC & $0.38 \pm 0.01^{\triangle \boldsymbol{\Delta}}$ & $2.37 \pm 0.22^{\triangle \boldsymbol{\Delta}}$ & $2.36 \pm 0.08^{\boldsymbol{\Lambda}}$ \\
\hline
\end{tabular}

${ }^{\triangle} P<0.05$ versus BC. ${ }^{\wedge} P<0.05$ versus MODEL.

\section{Results}

\subsection{Pharmacodynamics of RYNXC}

3.1.1. Microcirculation Perfusion of Mammary Tissues. The nipple numbers of each group were 16 . It was shown that the microcirculation perfusion of mammary tissues among groups was significantly different $(F=3.84 ; P=0.0139)$. MODEL, TAM, and RYNXC groups showed significant decrease compared with BC group $(P<0.05)$. There was no significant difference among MODEL, TAM, and RYNXC groups $(P>0.05)$ (Table 1$)$.

3.1.2. Hemorheology. It was shown that the hematocrit (HCT) among groups was significantly different $(F=107.49 ; P=$ $0.000)$. MODEL, TAM, and RYNXC groups showed significant increase compared with $\mathrm{BC}$ group $(P=0.000)$. TAM and RYNXC groups showed significant decrease compared with MODEL group $(P<0.05)$. RYNXC group showed significant decrease compared with TAM group $(P=0.024)$.

It was shown that the fibrinogen (FIB) among groups was significantly different $(F=33.05 ; P=0.000)$. MODEL, TAM, and RYNXC groups showed significant increase compared with BC group $(P<0.05)$. TAM and RYNXC groups showed significant decrease compared with MODEL group $(P=0.000)$. There was no significant difference between TAM and RYNXC groups $(P=0.126)$.

It was shown that the erythrocyte aggregation index (EAI) among groups was significantly different $(F=7.34 ; P=0.001)$. MODEL group showed significant increase compared with BC group $(P=0.001)$. TAM and RYNXC groups showed no significant increase compared with $\mathrm{BC}$ group $(P>$ 0.05). TAM and RYNXC groups showed significant decrease compared with MODEL group $(P=0.000)$. There was no significant difference between RYNXC and TAM groups $(P=$ 0.093) (Table 2).

3.1.3. Organ Coefficient. It was shown that the spleen coefficient among groups was significantly different $(F=7.40 ; P=$
TABLE 3: Results of organ coefficients in rats $(n=8, \bar{X} \pm \mathrm{SD})$.

\begin{tabular}{|c|c|c|c|}
\hline Group & Spleen & Liver & Uterus \\
\hline $\mathrm{BC}$ & $1.79 \pm 0.47$ & $27.80 \pm 1.75$ & $2.89 \pm 0.87$ \\
\hline MODEL & $3.08 \pm 1.18^{\triangle}$ & $31.59 \pm 5.22$ & $20.53 \pm 3.84^{\triangle}$ \\
\hline TAM & $1.65 \pm 0.27^{\mathbf{A}}$ & $31.21 \pm 4.69$ & $1.44 \pm 0.58^{\triangle \boldsymbol{\Delta}}$ \\
\hline RYNXC & $2.00 \pm 0.37^{\boldsymbol{\Lambda}}$ & $28.49 \pm 1.95$ & $2.87 \pm 1.36^{\boldsymbol{\Lambda}}$ \\
\hline
\end{tabular}

0.001). MODEL group showed significant increase compared with BC group $(P=0.012)$. TAM and RYNXC groups showed no significant difference compared with BC group $(P>$ 0.05). TAM and RYNXC groups showed significant decrease compared with MODEL group $(P<0.05)$. There was significant difference between TAM and RYNXC groups $(P$ $=0.048)$.

It was shown that the liver coefficient among groups was not significantly different $(F=2.07 ; P=0.1264)$. MODEL, TAM, and RYNXC groups showed no significant increase compared with BC group $(P>0.05)$. TAM and RYNXC groups showed no significant difference compared with MODEL group $(P>0.05)$. There was no significant difference between TAM and RYNXC groups $(P=0.076)$.

It was shown that the uterus coefficient among groups was significantly different $(F=149.01 ; P=0.000)$. Compared with BC group, MODEL group showed significant increase $(P=0.000)$, TAM group showed significant decrease $(P=$ $0.002)$, and RYNXC group showed no significant difference $(P=0.890)$. TAM and RYNXC groups showed significant decrease compared with MODEL group $(P=0.000)$. And there was significant difference between TAM and RYNXC groups $(P=0.010)$ (Table 3$)$.

3.1.4. Pathological Observation. H\&E staining was performed. Invasive carcinoma was not found in pathological observations of all rats' mammary tissues. Ductal carcinoma was observed in situ in MODEL group, and atypical hyperplasia was observed in TAM and RYNXC groups (Figure 2).

\subsection{Medicinal Chemistry of RYNXC}

3.2.1. Optimization of the HPLC Conditions. The extract of RYNXC was injected into HPLC system. Sample volume was $10 \mu \mathrm{L}$, flow rate was $0.8 \mathrm{~mL} / \mathrm{min}$, and column temperature was $30^{\circ} \mathrm{C}$. Five wavelengths $(208,220,254,280$, and $365 \mathrm{~nm})$ were tested for the best detection sensitivity, although all the compounds have different UV absorption characteristics, and the detection wavelength of $280 \mathrm{~nm}$ gave the optimal results except for peaks 14 and 15, in which evaporative light scattering detector (ELSD) gave more accurate detection. Moreover, the ELSD chromatogram of the extract in RYNXC showed that several compounds that had low response were not marked (compounds 4-11) (Figure 3).

3.2.2. Characterization of the Compounds in RYNXC. Peaks are separated and detected according to the spectrum of each peak in the total ion chromatograms (TICs). In the TICs, some ion peaks of compounds which had low intensity 


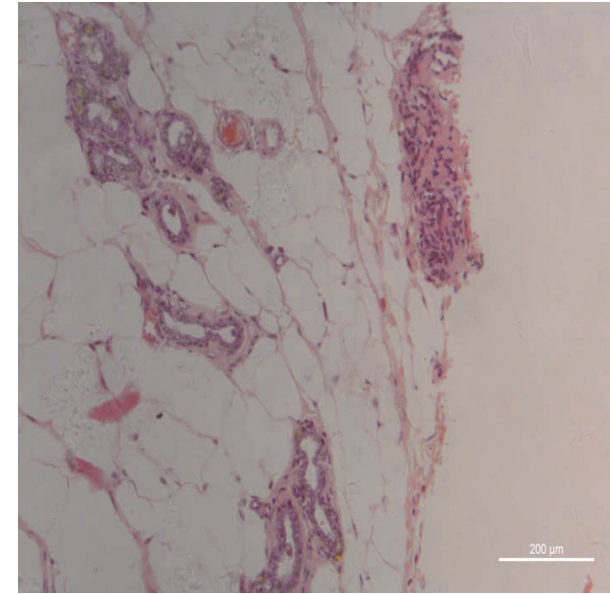

(a)

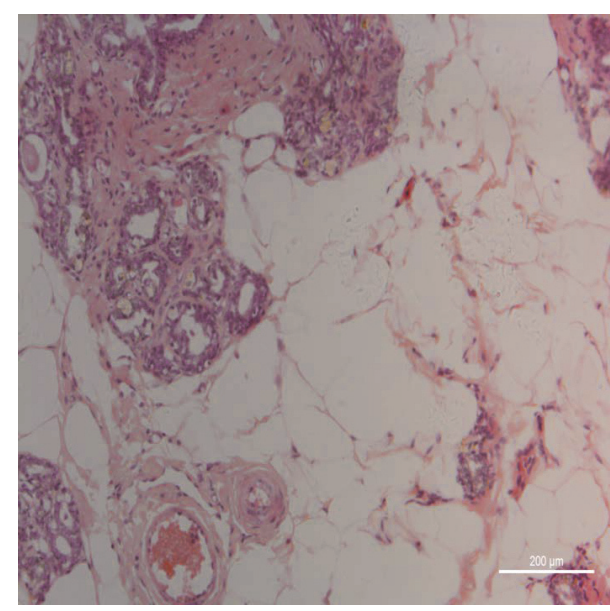

(c)

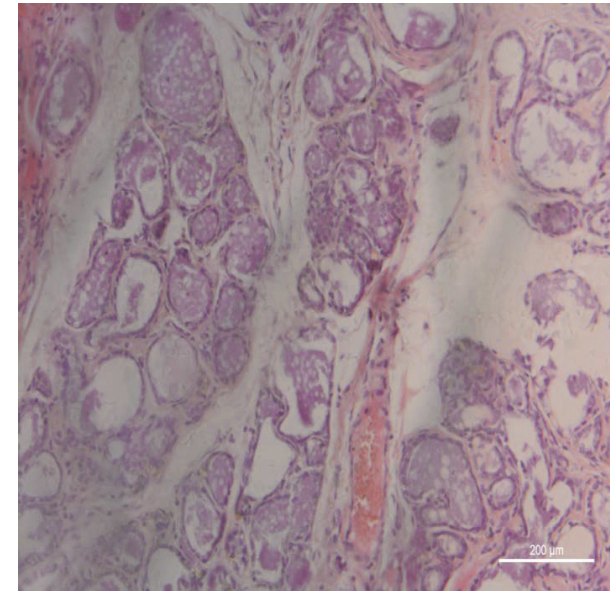

(b)

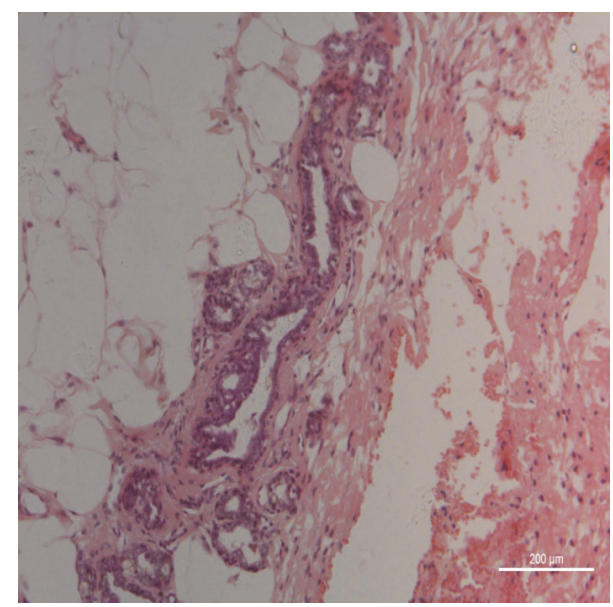

(d)

Figure 2: Mammary tissues (HE ×200). (a) BC. (b) MODEL. (c) TAM. (d) RYNXC.

were not marked in the figure (compounds 2-4 and 9) (Figure 4). Among them, fifteen compounds, 5 organic acids, 1 tannin, 1 alkaloid, 1 volatile oil, 3 anthraquinones, and 4 flavonoids, were tentatively identified. Fifteen compounds were detected by DAD and ELSD. The compounds were all reported previously from the ingredient herbs of RYNXC and were tentatively characterized by comparison with reference substances based on their HPLC retention time and MS fragmentation patterns. The features of the ESI-MS data were mainly $[\mathrm{M}-\mathrm{H}]^{-}$ions, $[\mathrm{M}+\mathrm{H}]^{+}$ions, and $[\mathrm{M}+\mathrm{Na}]^{+}$ions. The retention times, molecular weights, identification, and formulas are presented in Table 4.

\section{Discussion}

In this pharmacodynamics study, RYNXC group showed significant improvement in HCT $(P<0.05)$, FIB $(P<0.05)$, EAI $(P<0.05)$, spleen coefficient $(P<0.05)$, and uterus coefficient $(P<0.05)$ compared with MODEL group. And in pathological observation, ductal carcinoma was observed in situ in MODEL group and atypical hyperplasia was observed in RYNXC and TAM groups. Therefore, RYNXC was an effective Chinese herbal formula for mammary precancerous lesions.

The compatibility of traditional Chinese medicine refers to the combination of multiple herbs, based on clinical effects and the properties of herbs. The formulating herbs in RYNXC have effects of relieving the suppressed liver, activating blood circulation, and regulating the thoroughfare. It is important to study medicinal chemistry of RYNXC so as to understand its biological and medical significance. However, chemical analysis and quality control studies on RYNXC are limited. HPLC-MS is popular for direct identification of multiple components and for the quality control of Chinese herbs because it has wide suitability and sensitivity and provides sufficient structural information. DAD supports peak characterization of the sharpest peaks of fast separations for reliable sample data. ELSD could detect sample concentration with or without UV absorption. ESI can lead to only protonated or deprotonated molecules [10, 11]. Therefore, HPLC-ESI-MS is one of the most efficient analytical techniques available for the analysis of Chinese herbal formulas and provides a 


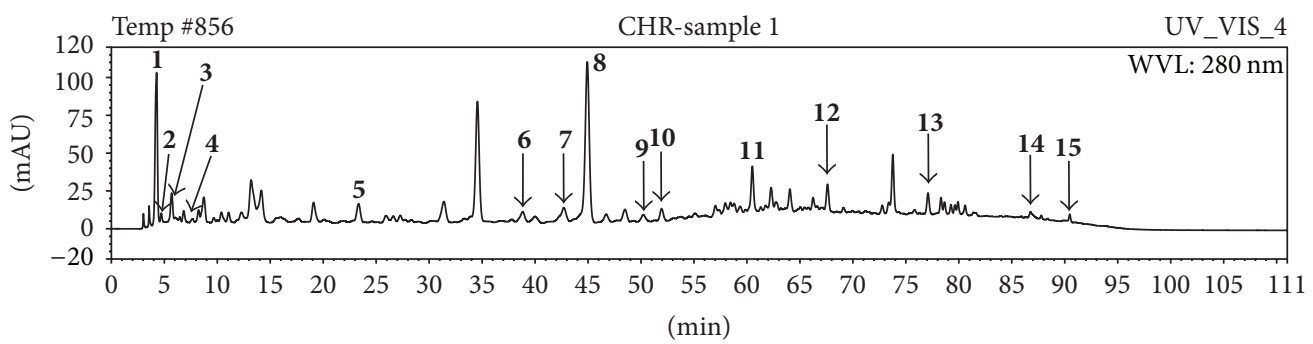

(a) $280 \mathrm{~nm}$

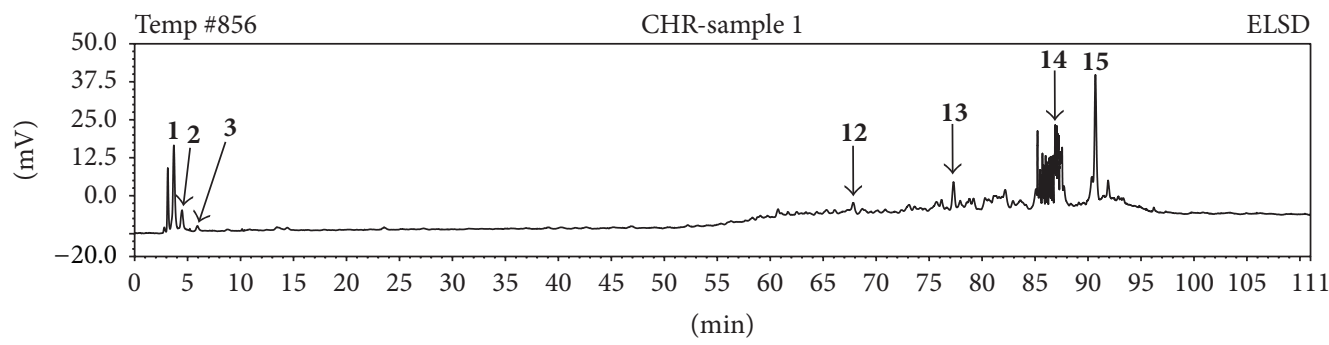

(b) ELSD

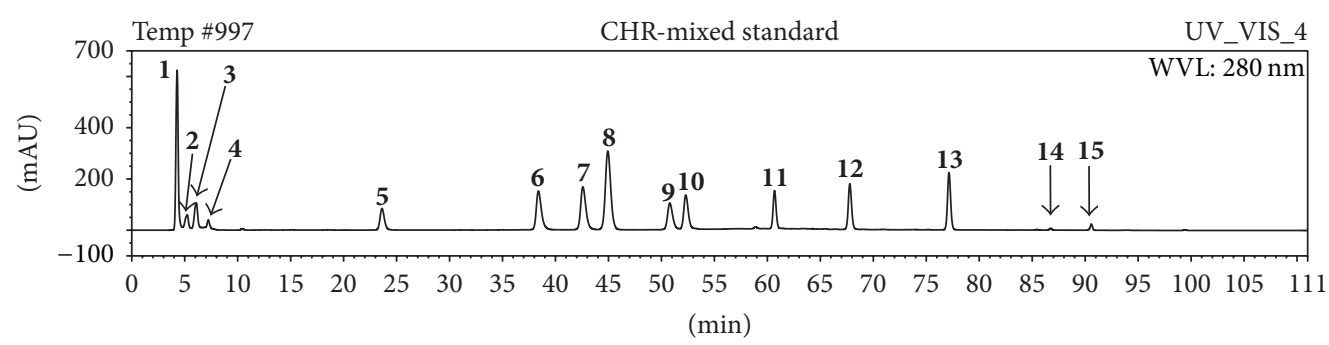

(c) $280 \mathrm{~nm}$

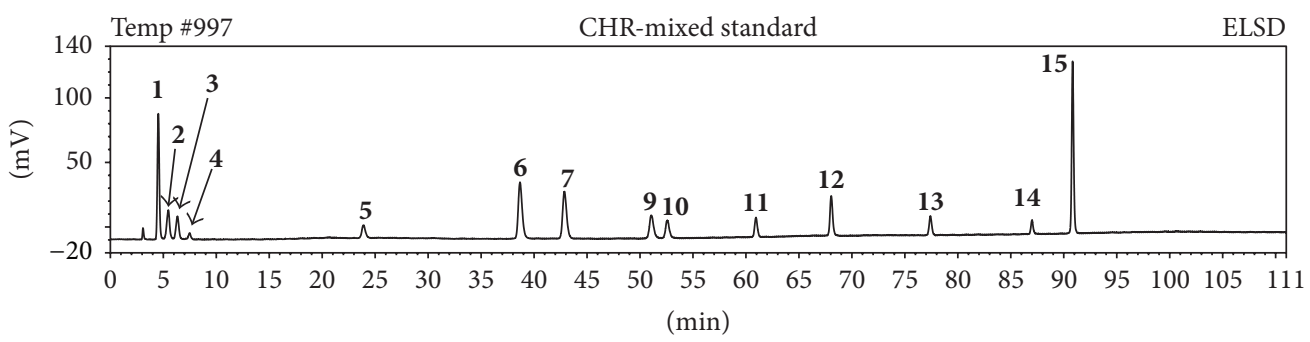

(d) ELSD

FIGURE 3: (a) HPLC chromatogram of the extract in RYNXC at $280 \mathrm{~nm}$. (b) HPLC chromatogram of the extract in RYNXC by ELSD. (c) HPLC chromatogram of fifteen reference substances at $280 \mathrm{~nm}$. (d) HPLC chromatogram of fifteen reference substances by ELSD.

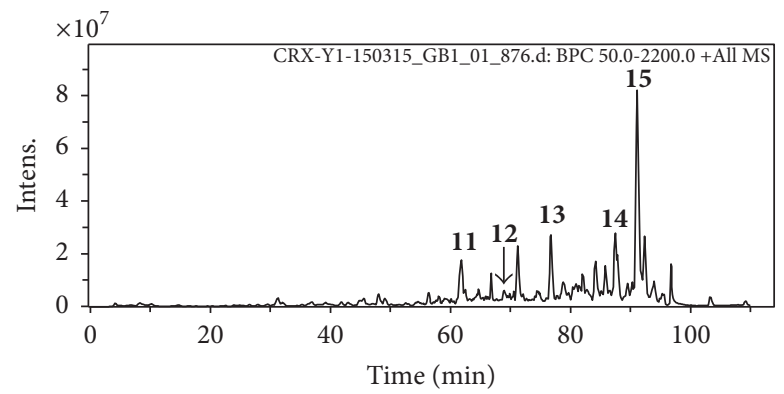

(a) TIC $(+)$

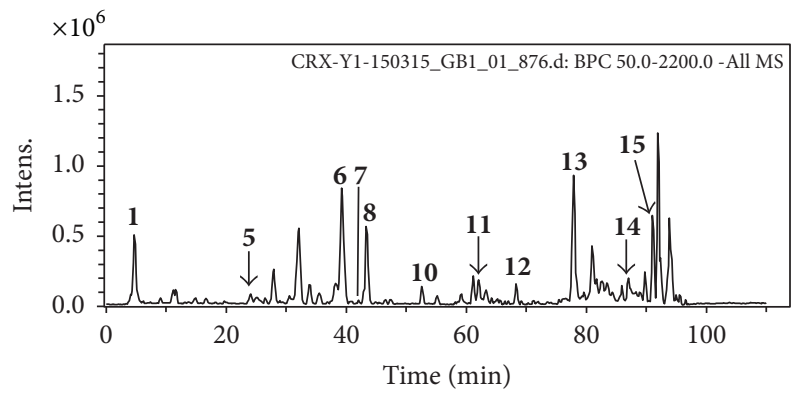

(b) TIC (-)

FIgURE 4: Total ion chromatogram of the extract in RYNXC. (a) Positive mode. (b) Negative mode. 
TABLE 4: Identification of the multiple constituents in RYNXC.

\begin{tabular}{|c|c|c|c|c|c|}
\hline Analyte & $T_{R}(\min )$ & Parent ions $m / z$ & M.W. (Da) & ID & Formula \\
\hline 1 & 4.27 & {$[\mathrm{M}-\mathrm{H}]^{-} 168.9,[\mathrm{M}+\mathrm{H}]^{+} 170.9$} & 170.12 & Gallic acid & $\mathrm{C}_{7} \mathrm{H}_{6} \mathrm{O}_{5}$ \\
\hline 2 & 5.32 & {$[\mathrm{M}-\mathrm{H}]^{-} 289.0,[\mathrm{M}+\mathrm{H}]^{+} 291.0$} & 290.27 & Cianidanol & $\mathrm{C}_{15} \mathrm{H}_{14} \mathrm{O}_{6}$ \\
\hline 3 & 6.02 & {$[\mathrm{M}-\mathrm{H}]^{-} 353.1,[\mathrm{M}+\mathrm{H}]^{+} 355.1$} & 354.31 & Chlorogenic acid & $\mathrm{C}_{16} \mathrm{H}_{18} \mathrm{O}_{9}$ \\
\hline 4 & 7.89 & {$[\mathrm{M}+\mathrm{H}]^{+} 356.1$} & 355.43 & Tetrahydropalmatine & $\mathrm{C}_{21} \mathrm{H}_{25} \mathrm{NO}_{4}$ \\
\hline 5 & 23.52 & {$[\mathrm{M}-\mathrm{H}]^{-} 359.5,[\mathrm{M}+\mathrm{Na}]^{+} 383.2$} & 360.31 & Rosmarinic acid & $\mathrm{C}_{18} \mathrm{H}_{16} \mathrm{O}_{8}$ \\
\hline 6 & 38.14 & {$[\mathrm{M}-\mathrm{H}]^{-} 301.3,[\mathrm{M}+\mathrm{H}]^{+} 303.3$} & 302.24 & Quercetin & $\mathrm{C}_{15} \mathrm{H}_{10} \mathrm{O}_{7}$ \\
\hline 7 & 42.44 & {$[\mathrm{M}-\mathrm{H}]^{-} 285.0,[\mathrm{M}+\mathrm{H}]^{+} 287.0$} & 286.24 & Luteolin & $\mathrm{C}_{15} \mathrm{H}_{10} \mathrm{O}_{6}$ \\
\hline 8 & 45.22 & {$[M+102]^{+} 266.0$} & 164.2 & Eugenol & $\mathrm{C}_{10} \mathrm{H}_{12} \mathrm{O}_{2}$ \\
\hline 9 & 50.68 & {$[\mathrm{M}-\mathrm{H}]^{-} 285.4,[\mathrm{M}+\mathrm{H}]^{+} 287.1$} & 286.24 & Kaempferol & $\mathrm{C}_{15} \mathrm{H}_{10} \mathrm{O}_{6}$ \\
\hline 10 & 52.44 & {$[\mathrm{M}-\mathrm{H}]^{-}$268.9, $[\mathrm{M}+\mathrm{H}]^{+} 270.9$} & 270.24 & Apigenin & $\mathrm{C}_{15} \mathrm{H}_{10} \mathrm{O}_{5}$ \\
\hline 11 & 60.70 & {$[\mathrm{M}-\mathrm{H}]^{-}$269.6, $[\mathrm{M}+\mathrm{H}]^{+} 270.9$} & 270.24 & Aloe-emodin & $\mathrm{C}_{15} \mathrm{H}_{10} \mathrm{O}_{5}$ \\
\hline 12 & 67.75 & {$[\mathrm{M}-\mathrm{H}]^{-}$283.1, $[\mathrm{M}+\mathrm{H}]^{+} 284.9$} & 284.22 & Rhein & $\mathrm{C}_{15} \mathrm{H}_{8} \mathrm{O}_{6}$ \\
\hline 13 & 77.18 & {$[\mathrm{M}-\mathrm{H}]^{-}$269.0, $[\mathrm{M}+\mathrm{H}]^{+} 271.0$} & 270.24 & Emodin & $\mathrm{C}_{15} \mathrm{H}_{10} \mathrm{O}_{5}$ \\
\hline 14 & 86.61 & {$[\mathrm{M}-\mathrm{H}]^{-} 470.7,[\mathrm{M}+\mathrm{H}]^{+} 471.3$} & 470.68 & KBA & $\mathrm{C}_{30} \mathrm{H}_{46} \mathrm{O}_{4}$ \\
\hline 15 & 90.32 & {$[\mathrm{M}+\mathrm{H}]^{+}$513.3, $[2 \mathrm{M}-\mathrm{H}]^{-} 1024.6$} & 512.72 & AKBA & $\mathrm{C}_{32} \mathrm{H}_{48} \mathrm{O}_{5}$ \\
\hline
\end{tabular}

rapid method to separate and identify multiple constituents in RYNXC.

Modern phytochemistry studies showed that herbs in RYNXC contain multiple bioactive constituents. This study identified fifteen compounds in RYNXC: gallic acid, cianidanol, chlorogenic acid, tetrahydropalmatine, rosmarinic acid, quercetin, luteolin, eugenol, kaempferol, apigenin, aloe-emodin, rhein, emodin, 11-keto- $\beta$-boswellic acid, and 3 -acetyl-11-keto- $\beta$-boswellic acid. The compounds can be classified as organic acids, tannin, alkaloid, volatile oil, anthraquinones, and flavonoids. Among them, volatile oils have been commonly accepted as bioactive constituents in pharmacology, such as eugenol, which was confirmed to have tumor suppression effect $[12,13]$.

Anthraquinone, tannins, and polysaccharide were confirmed to inhibit proliferation of cancer cell and induce apoptosis [14]. Gallic acid and cianidanol were confirmed to have antitumor and antioxidant effects $[15,16]$. Alkaloids, such as tetrahydropalmatine, have been approved to inhibit proliferation of cancer cells [17]. Flavonoids are approved as bioactive components, such as apigenin, which was confirmed to inhibit cancer cell proliferation, migration, and invasion [18]. Flavonoid glycosides were confirmed to have antioxidant effect [19]. Boswellic acids, including 11-keto- $\beta$ boswellic acid (KBA) and 3 -acetyl-11-keto- $\beta$-boswellic acid (AKBA), were approved to have the effect of inhibiting proliferation of cancer cell $[20,21]$. Eugenol in Commiphora myrrha Engl. is a typical active constituent. The extract of Commiphora myrrha Engl. showed significant cytotoxicity of breast cancer cells $[22,23]$.

In summary, the study revealed that RYNXC was efficacious in improving HCT, FIB, EAI, spleen coefficient, and uterus coefficient and inhibiting the development of carcinoma in mammary tissues. Therefore, RYNXC is an effective Chinese herbal formula for mammary precancerous lesions. Moreover, we identified fifteen compounds in
RYNXC: gallic acid, cianidanol, chlorogenic acid, tetrahydropalmatine, rosmarinic acid, quercetin, luteolin, eugenol, kaempferol, apigenin, aloe-emodin, rhein, emodin, 11-keto$\beta$-boswellic acid, and 3-acetyl-11-keto- $\beta$-boswellic acid. This study provides a scientific basis for the quality standard and pharmacodynamics of RYNXC. It will be helpful to the clinical application of RYNXC for treating mammary precancerous lesions in the future.

\section{Conflicts of Interest}

The authors declare that there are no conflicts of interest.

\section{Authors' Contributions}

Min Ma contributed to study concept; Ruixue Chen and Guijuan Zhang contributed to study design and performance. All authors contributed to analysis of data; Ruixue Chen contributed to drafting of the paper; Min Ma contributed to study supervision. All authors approved the final version to be published. Ruixue Chen and Guijuan Zhang contributed equally to this work.

\section{Acknowledgments}

This work was financially supported by the National Natural Science Foundation of China (nos. 81673979, 81173265, 81473688, and 81373314), the Education Program of China for New Century Excellent Talents (no. NCET-13-0827), the Traditional Chinese Medicine Administration Project of Guangdong, China (no. 20141070), the Science and Technology Program of Guangzhou, China (no. 2014J4100104), the Science and Technology Program of Guangdong, China (nos. 2014A020212672, 2014A020210015, and 2013B090500105), the Research Cultivation and Innovation-Medical Joint Foundation of Jinan University, Guangzhou, China (no. 21615464), 
the Natural Science Foundation of Guangdong, China (nos. 2016A030313114 and 2015A030313333), and Guangzhou Municipal Enterprise Research and Development Institutions Construction Project (no. 201503010064).

\section{References}

[1] R. L. Siegel, K. D. Miller, and A. Jemal, "Cancer statistics, 2016," CA: A Cancer Journal for Clinicians, vol. 66, no. 1, pp. 7-30, 2016.

[2] HC. Pan, RG. Gray, and C. Davies, "Predictors of recurrence during years 5-14 in 46, 138 women with $\mathrm{ER}^{+}$breast cancer allocated 5 years only of endocrine therapy (ET)," Journal of Clinical Oncology, vol. 34, 2016.

[3] S. R. Lakhani, "The transition from hyperplasia to invasive carcinoma of the breast," Journal of Pathology, vol. 187, no. 3, pp. 272-278, 1999.

[4] H.-P. Sinn and H. Kreipe, "A brief overview of the WHO classification of breast tumors, 4th edition, focusing on issues and updates from the 3rd edition," Breast Care, vol. 8, no. 2, pp. 149-154, 2013.

[5] P. R. Portschy, S. Marmor, R. Nzara, B. A. Virnig, and T. M. Tuttle, "Trends in incidence and management of lobular carcinoma in situ: A population-based analysis," Annals of Surgical Oncology, vol. 20, no. 10, pp. 3240-3246, 2013.

[6] D. Sharma, B. M. G. Smits, M. R. Eichelberg et al., "Quantification of epithelial cell differentiation in mammary glands and carcinomas from DMBA- and MNU-exposed rats," PLOS ONE, vol. 6, no. 10, Article ID e26145, 2011.

[7] R. Viedma-RodríGuez, L. Baiza-Gutman, F. Salamanca-Gómez et al., "Mechanisms associated with resistance to tamoxifen in estrogen receptor-positive breast cancer (review)," Oncology Reports, vol. 32, no. 1, pp. 3-15, 2014.

[8] Y. W. Hua, Z. D. Zhang, Y. Kong et al., "Secondary prevention and treatment of precancerous lesions of breast cancer," International Journal of Surgery, vol. 38, no. 9, pp. 608-611, 2011.

[9] S. Kamali, O. Bender, G. H. Kamali, M. T. Aydin, O. Karatepe, and E. Yuney, "Diagnostic and therapeutic value of ductoscopy in nipple discharge and intraductal proliferations compared with standard methods," Breast Cancer, vol. 21, no. 2, pp. 154161, 2014

[10] Y.-J. Yang, X.-W. Liu, B. Li et al., "Simultaneous determination of diaveridine, trimethoprim and ormetoprim in feed using high performance liquid chromatography tandem mass spectrometry," Food Chemistry, vol. 212, pp. 358-366, 2016.

[11] R. Nortes-Méndez, J. Robles-Molina, R. López-Blanco, A. Vass, A. Molina-Díaz, and J. F. Garcia-Reyes, "Determination of polar pesticides in olive oil and olives by hydrophilic interaction liquid chromatography coupled to tandem mass spectrometry and high resolution mass spectrometry," Talanta, vol. 158, pp. 222-228, 2016.

[12] R. Ghosh, M. Ganapathy, W. L. Alworth, D. C. Chan, and A. P. Kumar, "Combination of 2-methoxyestradiol $\left(2-\mathrm{ME}_{2}\right)$ and eugenol for apoptosis induction synergistically in androgen independent prostate cancer cells," The Journal of Steroid Biochemistry and Molecular Biology, vol. 113, no. 1-2, pp. 25-35, 2009.

[13] A. Hussain, K. Brahmbhatt, A. Priyani, M. Ahmed, T. A. Rizvi, and C. Sharma, "Eugenol enhances the chemotherapeutic potential of gemcitabine and induces anticarcinogenic and antiinflammatory activity in human cervical cancer cells," Cancer Biotherapy and Radiopharmaceuticals, vol. 26, no. 5, pp. 519-527, 2011.
[14] P.-L. Kuo, T.-C. Lin, and C.-C. Lin, "The antiproliferative activity of aloe-emodin is through p53-dependent and p21dependent apoptotic pathway in human hepatoma cell lines," Life Sciences, vol. 71, no. 16, pp. 1879-1892, 2002.

[15] N. Mahmood, S. Piacente, C. Pizza, A. Burke, A. I. Khan, and A. J. Hayt, "The anti-HIV activity and mechanisms of action of pure compounds isolated from Rosa damascena," Biochemical and Biophysical Research Communications, vol. 229, no. 1, pp. 73-79, 1996.

[16] L. Li, T. B. Ng, W. Gao et al., "Antioxidant activity of gallic acid from rose flowers in senescence accelerated mice," Life Sciences, vol. 77, no. 2, pp. 230-240, 2005.

[17] Y. Zhao, J. Gao, J. Ji et al., "Cytotoxicity enhancement in MDAMB-231 cells by the combination treatment of tetrahydropalmatine and berberine derived from Corydalis yanhusuo W. T. Wang," Journal of Intercultural Ethnopharmacology, vol. 3, no. 2, pp. 68-72, 2014.

[18] M. Xu, S. Wang, Y. Song, J. Yao, K. Huang, and X. Zhu, "Apigenin suppresses colorectal cancer cell proliferation, migration and invasion via inhibition of the Wnt/ $\beta$-catenin signaling pathway," Oncology Letters, vol. 11, no. 5, pp. 3075-3080, 2016.

[19] C. N. A. Leong, M. Tako, I. Hanashiro, and H. Tamaki, "Antioxidant flavonoid glycosides from the leaves of Ficus pumila L.," Food Chemistry, vol. 109, no. 2, pp. 415-420, 2008.

[20] A. Y. Fan, L. Lao, R. X. Zhang et al., "Effects of an acetone extract of Boswellia carterii Birdw. (Burseraceae) gum resin on adjuvant-induced arthritis in lewis rats," Journal of Ethnopharmacology, vol. 101, no. 1-3, pp. 104-109, 2005.

[21] Y. Shao, C. Ho, C. Chin, V. Badmaev, W. Ma, and M. Huang, "Inhibitory activity of boswellic acids from Boswellia serrata against human leukemia HL-60 cells in culture," Planta Medica, vol. 64, no. 4, pp. 328-331, 1998.

[22] N. Zhu, M. M. Rafi, R. S. DiPaola et al., "Bioactive constituents from gum guggul (Commiphora wightii)," Phytochemistry, vol. 56, no. 7, pp. 723-727, 2001.

[23] S. L. Su, T. J. Wang, T. Chen et al., "Cytotoxicity activity of extracts and compounds from Commiphora myrrh resin against human gynecologic cancer cells," Journal of Medicinal Plants Research, vol. 5, no. 8, pp. 1382-1389, 2011. 


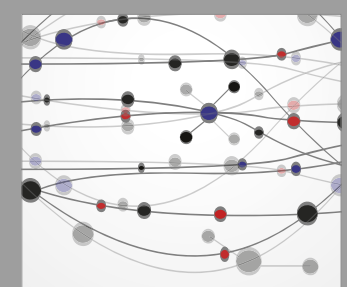

The Scientific World Journal
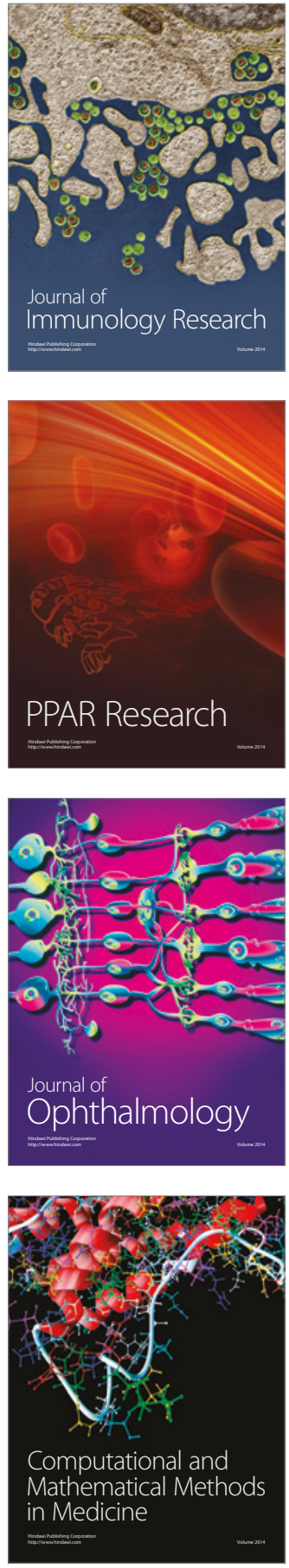

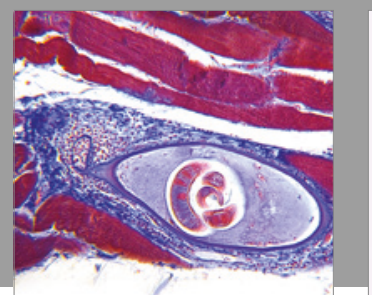

Gastroenterology Research and Practice
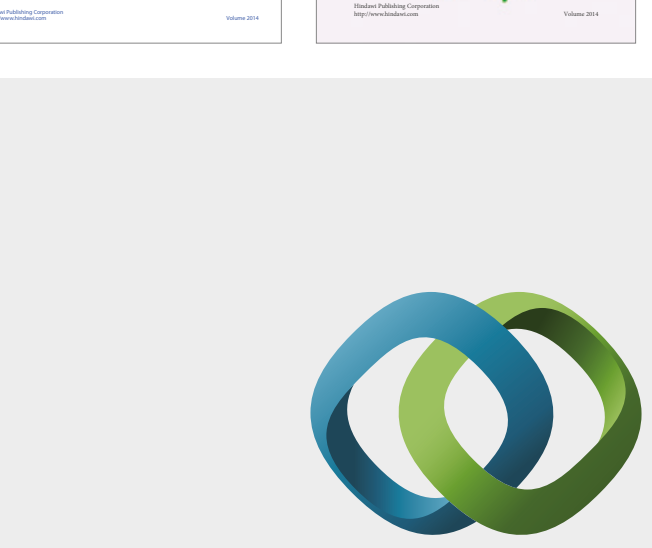

\section{Hindawi}

Submit your manuscripts at

https://www.hindawi.com
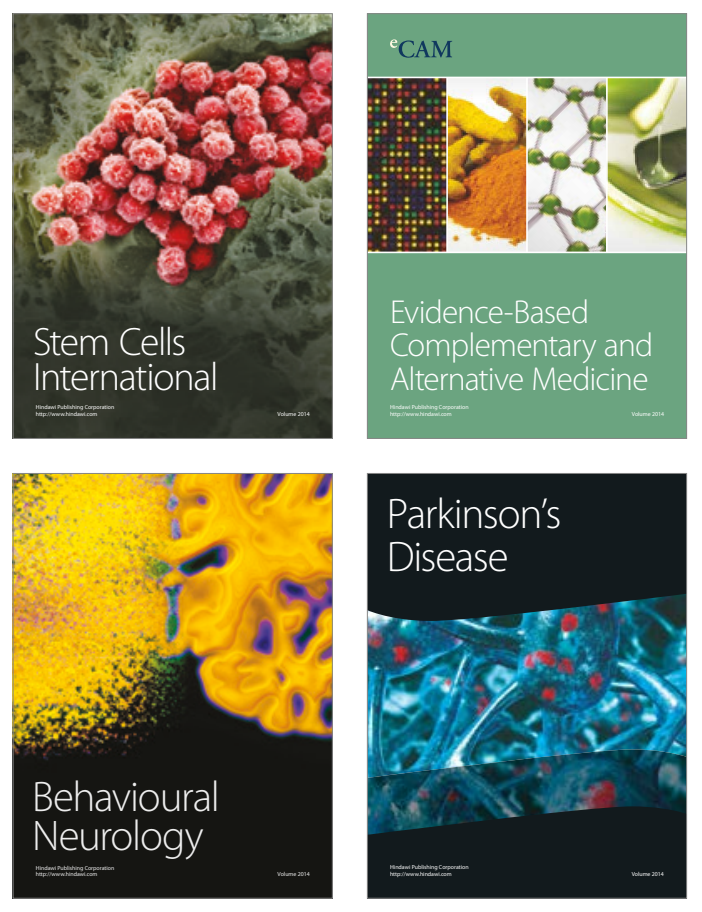
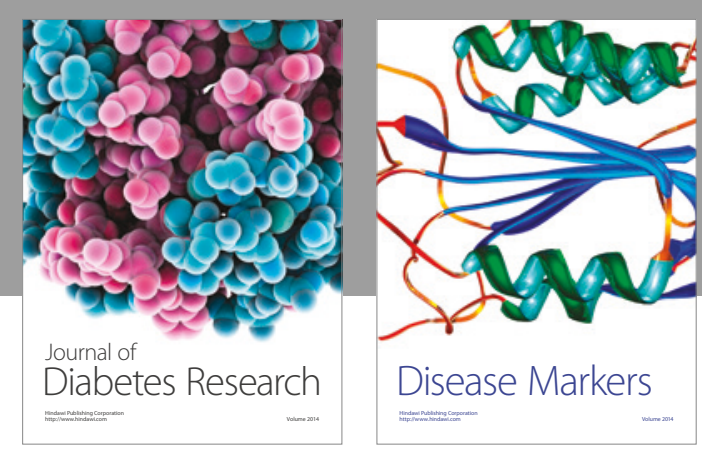

Disease Markers
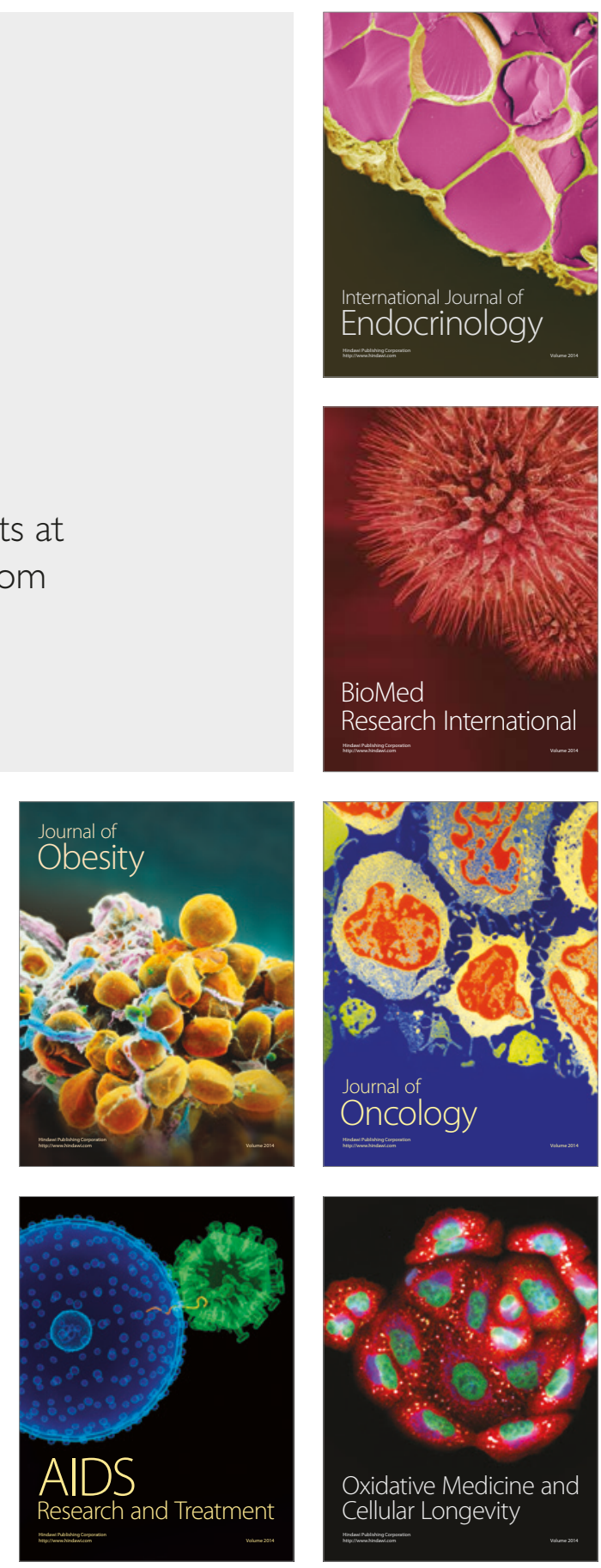